\title{
Preparation of Baking-Free Brick from Manganese Residue and Its Mechanical Properties
}

\author{
Ping Wang ${ }^{1,2}$ and Dong-yan Liu ${ }^{1}$ \\ ${ }^{1}$ Department of Civil Engineering, Chongqing University, Chongqing 401300, China \\ ${ }^{2}$ Department of Architecture \& Civil Engineering, Logistical Engineering University, Chongqing 401331, China \\ Correspondence should be addressed to Dong-yan Liu; cqudyliu@yahoo.com.cn
}

Received 12 December 2012; Revised 21 February 2013; Accepted 3 March 2013

Academic Editor: Wen Zeng

Copyright (C) 2013 P. Wang and D.-y. Liu. This is an open access article distributed under the Creative Commons Attribution License, which permits unrestricted use, distribution, and reproduction in any medium, provided the original work is properly cited.

The increasing amount of waste residue produced during the electrolytic preparation process of manganese has nowadays brought about serious environmental problems. The research on utilization of manganese slag has been a hot spot around the world. The utilization of manganese slag is not only environment friendly, but also economically feasible. In the current work, a summarization of the main methods to produced building materials from manganese slag materials was given. Baking-free brick, a promising building material, was produced from manganese slag with the addition of quicklime and cement. The physical properties, chemical composition, and mechanical performances of the obtained samples were measured by several analyses and characterization methods. Then the influence of adding materials and molding pressure during the preparation of baking-free brick samples on their compressive strength properties was researched. It is concluded that the baking-free brick prepared from manganese residue could have excellent compressive strength performance under certain formula.

\section{Introduction}

China has the largest amount of electrolytic manganese in production, consummation, and exportation. The total quantity of electrolytic manganese can be as huge as millions of tons every year, which account for up to $95 \%$ of that of the world [1-3]. It is also reported that Chinese electrolytic manganese production enterprises are mainly located in provinces like Hunan, Chongqing, Sichuan, Guizhou, and Yunnan. The production capacity and production amount of Chinese electrolytic manganese industry have a significant increase from 0.210 million tons in 2002 to 1.411 million tons in 2011, which can be seen in Table $1[4,5]$. The production of manganese metal is finical to our life. But, with the continuous increase production amount, the grade of available manganese ore has been decreased to only $15 \%$ $20 \%$. This means that there will be $5 \sim 7 \mathrm{t}$ of acid residue prepared per $1 \mathrm{t}$ of electrolytic manganese, resulting in the formation of a great deal of electrolytic manganese residue.

Electrolytic manganese residue (EMR) can be defined as the acid residue obtained during the preparation of electrolytic manganese, which is a process of adding mineral powders containing manganese carbonate into the sulfuric acid. It is also an inert salic material, more than $80 \%$ of whose particle size is below $80 \mu \mathrm{m}$. On the other hand, EMR is full of sulfate, for the content of $\mathrm{SO}_{3}$ can be up to $15 \%$ 25\% [6]. However, EMR has a complicated composition due to its production process. The heavy metal ions in EMR would introduce terrible environmental pollution to the around soil and water after a long time of stockpiling and weathering. These soil and water rich of heavy metal ions could be a threat to human health. So for the purpose of reuse of manganese residue and reduction of its negative influences, research on the comprehensive utilization is an extremely interesting subject.

As a promising active material, EMR can be widely use in the production of building materials like cement, concrete, and brick [7-12]. The prepared cement and concrete could have excellent performance of corrosion resistance and mechanical properties $[13,14]$. As to the according research $[15,16]$, industrial residues such as EMR, slag can be used to produce the sintered brick, ceramic brick, steam-pressing 
TABLE 1: Production capacity and amount of the Chinese electrolytic manganese industry (million tons).

\begin{tabular}{lllllllllll}
\hline Year & 2002 & 2003 & 2004 & 2005 & 2006 & 2007 & 2008 & 2009 & 2010 & 2011 \\
\hline Production capacity & 0.300 & 0.450 & 0.550 & 0.921 & 1.049 & 1.570 & 1.879 & 2.110 & 2.200 & 2.230 \\
Production amount & 0.210 & 0.325 & 0.494 & 0.566 & 0.733 & 1.024 & 1.139 & 1.317 & 1.376 & 1.411 \\
\hline
\end{tabular}

TABLE 2: The physical properties of EMR.

\begin{tabular}{lcccccc}
\hline Physical properties & $\begin{array}{c}\text { Fineness } \\
(\%)\end{array}$ & $\begin{array}{c}\text { Density } \\
\left(\mathrm{g} / \mathrm{cm}^{3}\right)\end{array}$ & $\begin{array}{c}\text { Moisture content } \\
(\%)\end{array}$ & $\begin{array}{c}\text { Dry density } \\
\left(\mathrm{g} / \mathrm{cm}^{3}\right)\end{array}$ & $\begin{array}{c}\text { Cohesion } \\
(\mathrm{kPa})\end{array}$ & $\begin{array}{c}\text { Internal friction angle } \\
\left({ }^{\circ}\right)\end{array}$ \\
\hline EMR & 31.1 & 1.72 & 52.6 & 1.13 & 11.5 & 22.2 \\
\hline
\end{tabular}

brick, and baking-free brick. The method is to produce brick from the mixture of these industrial residues with shale and deposited mud. It is not only economically feasible, but also environmental friendly. Recently, many attempts have been made to prepared these kinds of bricks with better mechanical properties. Both Peng et al. [17] and Gao [18] have prepared sintered bricks using EMR, shale, and fly ash as raw materials. Their compressive strength can be up to 22.64 MPa. Zhang et al. [19] have done the research on the preparation of cameral brick materials from manganese slag. The mixing amount can be up to as much as $40 \%$. Wang et al. [20] obtained the steam-pressing brick from EMR with $10 \% \sim 20 \%$ of cement and $5 \% \sim 10 \%$ of quicklime. And the compressive strength can be about 20 30 MPa.

As to the preparation of baking-free brick, Jiang et al. [21] have found a new preparation method to obtain the compressive strength reaching up to $10 \mathrm{MPa}$. They mixed the EMR with fly ash, lime, and binding materials like lime cement followed by the addition of aggregate. Then the baking-free brick is obtained after the process of compression moulding. This process can dramatically enhance the strength and decrease the use of water. Generally, it is an effective way of resource utilization of EMR to obtain baking-free brick by the process of compression moulding [22]. In this paper, we have produced baking free brick from manganese slag with the addition of quicklime and cement and have measured the physical properties, chemical compositions, and mechanical performances of the obtained samples.

\section{The Preparation of EMR Brick}

2.1. Materials. The status of EMR is loose when it was first poured into the slag stocking site and will change into half flow conditions under the action of rainwater which is as shown in Figure 1(a). Then the manganese slag will solidify after a long time of evaporation. The surface can turn into a hardened state which is illustrated in Figure 1(b). And it is harder than the part under the surface.

Figure 2(a) reveals the vertical distribution pattern of the manganese residue. The sampling site is $30 \mathrm{~m}$ far from the slag dam and $0.8 \sim 1.2 \mathrm{~m}$ below the hardened surface. EMR in this site is black dope in the state of half flow as shown in Figure 2(b).

The physical performances and chemical composition of the taken samples are separately illustrated in Tables 2 and 3. From Table 2, it can be known that the density is $1.72 \mathrm{~g} / \mathrm{cm}^{3}$, and the moisture content can be around 52.6\%. And from Table 3 it can be seen that the main composition is $\mathrm{SiO}_{2}$ which is the main composition of brick. On the other hand, the cement used in these experiments is 42.5 ordinary Portland cement. The fineness modulus of sand is separately 3.1 and 1.1. The experimental quicklime containing $76.5 \%$ of active calcium oxide is sieved at a $0.8 \%$ residue. Its fineness is referring to the standard of cement.

2.2. Preparation of the Samples. The proportion of materials in this experimental is in dry status. As shown in Table 2, the moisture content of the taken EMR is $52.6 \%$. What is more the contents of $\mathrm{MnSO}_{4}$ and $\left(\mathrm{NH}_{4}\right)_{2} \mathrm{SO}_{4}$ are separately $3.75 \%$ and $2.47 \%$. As to the fabrication of EMR brick, the forming process is was semidry pressing process. The size of the performing tool was $\Phi 100 \mathrm{~mm} \times 100 \mathrm{~mm}$. The samples after forming were maintained by watering in the air. The strength is referring to the Mortar Strength Testing Method of Cement (GB/T17671-1999), performances testing to the Chinese National Standard of Wall Bricks Testing Methods (GB/T2542-2003), and the Detection Technological Standards of Building Structure (GB/T 50344-2004).

\section{Testing Properties of EMR Baking-Free Brick}

3.1. Raw Materials Systems. The low strength of brick from EMR-sand-lime system cannot afford the requirement of building materials. But the properties can be enhanced through adding $\sim 15 \%$ content of cement into the system [23]. As a building material, the fabrication process of baking-free brick is simple and becomes a hot spot of the researchers globally. In the previous studies, fly ash often acts as cementing materials [24]. However, due to the widely use of fly ash rather than cement and low production quantity of electrolytic manganese enterprise, it is critically important and low cost to produce the brick with the utilization of cement. The purpose of this paper is to investigate the influence of ratio and kinds of the raw materials on the mechanical properties of obtained bricks. According to the previous paper and the comparing experiments, it was proved that the system of EMR-sand-lime-cement is the best.

3.2. Forming Pressure. The early strength of EMR baking-free brick obtained in the process of forming pressure is due to the 
TABLE 3: The chemical composition of the EMR.

\begin{tabular}{|c|c|c|c|c|c|c|c|c|}
\hline Composition (\%) & $\mathrm{SiO}_{2}$ & $\mathrm{Al}_{2} \mathrm{O}_{3}$ & $\mathrm{Fe}_{2} \mathrm{O}_{3}$ & $\mathrm{CaO}$ & $\mathrm{MgO}$ & $\mathrm{MnO}$ & $\mathrm{SO}_{3}$ & Loss \\
\hline EMR & 38.4 & 14.3 & 6.78 & 9.45 & - & 3.75 & 19.2 & 10.12 \\
\hline
\end{tabular}

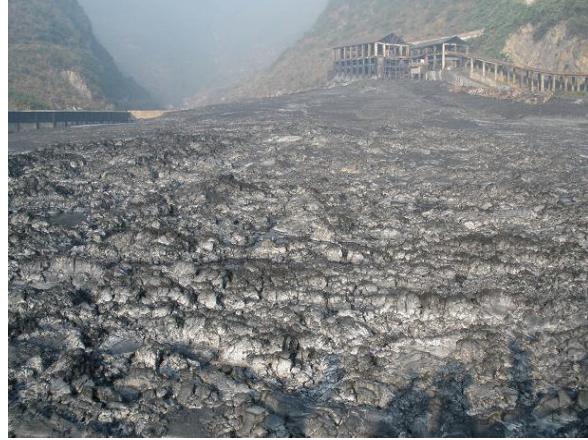

(a)

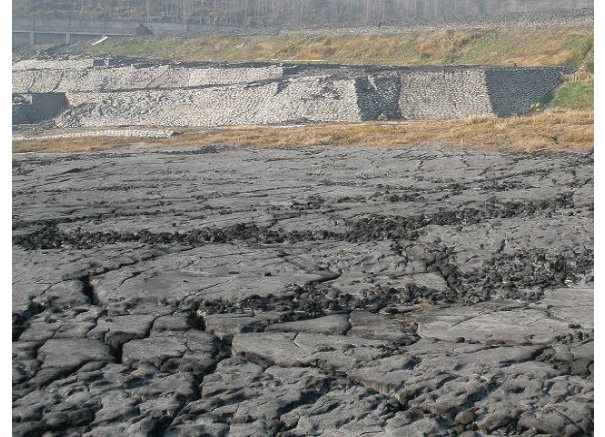

(b)

FIgUre 1: (a) Half flow conditions; (b) hardened state of surface.

TABLE 4: Compressive strength of bricks under different forming pressures.

\begin{tabular}{lcc}
\hline \multirow{2}{*}{ Forming pressure (MPa) } & \multicolumn{2}{c}{ Compressive strength (MPa) } \\
& $7 \mathrm{~d}$ & $28 \mathrm{~d}$ \\
\hline 20 & 10.6 & 16.3 \\
25 & 13.5 & 17.4 \\
30 & 14.7 & 21.3 \\
35 & 15.3 & 21.7 \\
40 & 16.2 & 22.3 \\
\hline
\end{tabular}

close contact of the raw particle materials [25]. It is beneficial to the physical and chemical reaction between these particles and simultaneously provides base for the later strength. The compressive strength of the bricks prepared under different forming pressures is shown in Table 4. From Table 4, it can be known that the $7 \mathrm{~d}$ and $28 \mathrm{~d}$ compressive strengths increase gradually along with the value of forming pressure. The rate of increase is low. But it is said that the larger the forming pressure is, the higher cost and the lower production the efficiency is. Comprehensively considering these factors, we conclude that the forming force of $25 \sim 30 \mathrm{MPa}$ can meet the requirement of architectural design. So it is believed to be the optimum range of moulding pressure.

3.3. Properties of EMR. Compressive strength testing was carried out on the baking-free brick fabricated by binding materials base on the previous forming pressure experiment. The binding material was obtained under different ratios of EMR-sand-lime-cement system. In the process, the ratio of water to solid is an important factor. Its value was determined in the range of $0.10 \sim 0.20$, according to case if the slurry would overflow from the forming mold. What is more the result also will differ under different ratio of cement to sand. The $7 \mathrm{~d}$ and $24 \mathrm{~d}$ compressive strengths under different formulas are stated in Table 5. It can also be seen that the average compressive strength of the as-obtained samples is over $10 \mathrm{MPa}$, which is up to the standard of building materials.

Table 5 illustrates that an optimum formula is $50 \%$ of EMR, $20 \%$ of river sand, $15 \%$ of quicklime, and $15 \%$ of cement, and ideal ratio of water to solid materials is $13 \%$. On the other hand, the result of test for heavy metal extraction meets the environmental criterion. The concentration of leaching $\mathrm{Mn}^{2+}$ is about $1.3 \mathrm{mg} / \mathrm{L}$, while that of the national discharged standard of sewage is $1.8 \mathrm{mg} / \mathrm{L}$. Consequently, the preparation of baking-free brick with excellent properties can be achieved using EMR as the main raw material.

The addition of aggregate can improve the particle size of mixture, reduce the contraction of the fabricated bricks, and enhance the mechanical behavior and durability of the samples. Due to the high proportion of aggregate and low proportion of cementing materials in Formula 1 and Formula 2 , only when reducing the ratio of water to cement can it meet the conditions of compression moulding. Even though it has a large value of $28 \mathrm{~d}$ strength, products from these two formulas have no practical applications because of the lacking of binding materials, tendency to loose, complex corporation of production process, and bad durability. While as to Formula 4 and Formula 5, the samples have more binding materials and less aggregate, leading to low strength. Shortage of framework materials and high demand of water are the main reasons. Above all, it can be concluded that the as-fabricated samples can have the largest $7 \mathrm{~d}$ and $28 \mathrm{~d}$ strength at a cement aggregate ratio of $1: 1$. It can be used in actual production using the formula of 50\% EMR, 25\% river sand, $10 \%$ quicklime, and $15 \%$ cement.

\section{Conclusion}

From the experiments and discussions in this paper, we can know that, in the production of EMR baking-free brick, 25 30 MPa of molding force is economically feasible, 


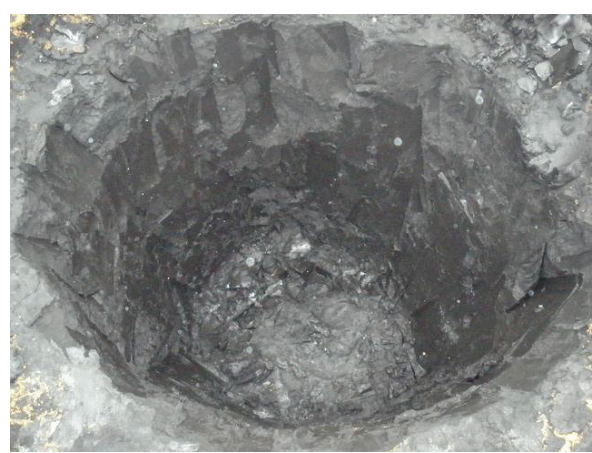

(a)

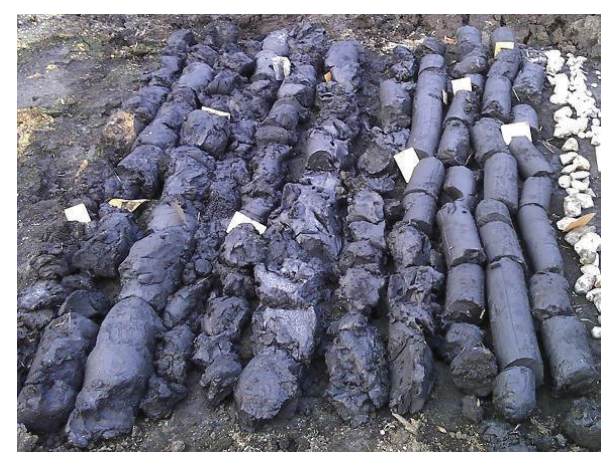

(b)

FIGURE 2: (a) Vertical distribution pattern of the manganese residue; (b) samples taken from $1.0 \mathrm{~m}$ below.

TABLE 5: Compressive strength under different ratios of cement to sand.

\begin{tabular}{|c|c|c|c|c|}
\hline \multirow{2}{*}{ Formula } & \multirow{2}{*}{ Cement-sand ratio } & \multirow{2}{*}{ Water-solid ratio } & \multicolumn{2}{|c|}{ Compressive strength (MPa) } \\
\hline & & & $7 \mathrm{~d}$ & $28 \mathrm{~d}$ \\
\hline 1 & $1: 2.0$ & 0.11 & 10.4 & 12.4 \\
\hline 2 & $1: 1.5$ & 0.12 & 11.9 & 15.3 \\
\hline 3 & $1: 1.0$ & 0.15 & 14.7 & 19.0 \\
\hline 4 & $1: 0.6$ & 0.18 & 14.3 & 18.1 \\
\hline 5 & $1: 0$ & 0.22 & 7.9 & 16.5 \\
\hline
\end{tabular}

and the pressure during forming process is beneficial to obtainment of the brick strength. Furthermore, when the cement aggregate ratio is $1: 1$ water solid ratio is 0.15 , and the moulding pressure is $30 \mathrm{MPa}$, the produced EMR baking-free bricks have excellent mechanical properties like compressive strength. What is more is EMR-sand-lime-cement production system is the optimum one with $50 \%$ of EMR, $25 \%$ of river sand, $10 \%$ of quicklime, and $15 \%$ of cement.

\section{References}

[1] A. Veysseyre, K. van de Velde, C. Ferrari, and C. Boutron, "Searching for manganese pollution from MMT anti-knock gasoline additives in snow from central Greenland," Science of the Total Environment, vol. 221, no. 2-3, pp. 149-158, 1998.

[2] N. Duan, W. Fan, Z. Changbo, Z. Chunlei, and Y. Hongbing, "Analysis of pollution materials generated from electrolytic manganese industries in China," Resources, Conservation and Recycling, vol. 54, no. 8, pp. 506-511, 2010.

[3] J. J. Jing and J. M. Xie, "Hazards of manganese pollution to health," Guangdong Trace Elements Science, vol. 15, no. 2, pp. 69, 2008.

[4] Z. Z. Tan, "The development of "11.5 plan" and the forecast of "12.5 plan" in Chinese EMM industry's," China's Manganese Industry, vol. 29, no. 1, pp. 1-4, 2011.

[5] J. Yang and Z. M. Zeng, "The situation analysis of EMM of China market in 2010," China's Manganese Industry, vol. 29, pp. 6-9, 2011.

[6] J. S. Qian, K. P. Hou, and Z. Wang, "Properties of electrolytic manganese slag used as building materials," Materials Review, vol. 23, pp. 59-61, 2009.

[7] T. P. Li, H. L. Xie, X. M. He, and X. Z. Zhou, "Experimental study of calcined electrolysis manganese residue and fly ash complex admixture," Bulletin of the Chinese Ceramic Society, vol. 26, pp. 567-573, 2007.

[8] Y. Z. Ouyang, X. W. Peng, J. B. Cao, Z. P. Li, and X. D. Deng, "Ultrasonic leaching of electrolytic manganese residue with additive," Environmental Protection of Chemical Industry, vol. 27, pp. 257-259, 2007.

[9] J. S. Qian, P. K. Hou, Z. Wang, and Y. Z. Qu, "Qu. Crystallization characteristic of glass-ceramic made from electrolytic manganese residue," Journal of Wuhan University of TechnologyMaterials Science Edition, vol. 27, pp. 45-49, 2012.

[10] P. K. Hou, J. S. Qian, Z. Wang, and C. Deng, "Production of quasi-sulfoaluminate cementitious materials with electrolytic manganese residue," Cement and Concrete Composites, vol. 34, pp. 248-254, 2012.

[11] Y. Wang, W. H. Ye, and J. Wan, "Method for manufacturing aerated concrete from electrolysis manganese slag," CN, 101698586 [P], 2010.

[12] Y. Wang, Y. S. Gao, L. Hengbo et al., "Water quenching manganese slag high performance concrete and preparation method," CN, 101844905 [P], 2010.

[13] Kh. S. A. E. Sherbini, "Simultaneous extraction of manganese from low grade manganese dioxide ore and beneficiation of sulphur slag," Separation and Purification Technology, vol. 27, no. 1, pp. 67-75, 2002.

[14] R. J. Liu, P. Chen, and Y. J. Wang, "Manufacture of light weight heat-insulating wall materials from water-quenched manganeseslags," CN, 101774208 [P], 2010.

[15] S. D. Li, H. Xiao, and R. Liu, "Recycling of fly ash, reservoir sludge and metallurgical tailings in manufacture of sintered decorative brick for dry walls," CN, 101666148 [P], 2010.

[16] K. Y. Chiang, K. L. Chien, and S. J. Hwang, "Study on the characteristics of building bricks produced from reservoir sediment," Journal of Hazardous Materials, vol. 159, no. 2-3, pp. 499-504, 2008. 
[17] B. Peng, L. Y. Chai, and J. Wang, "Method for treating industrial wastes, through sintering and solidifying, for the production of bricks," CN, 101775868 [P], 2010.

[18] H. L. Gao, "Production and consumption of manganese ore in and out of China," China Metal Bulletin, vol. 7, pp. 33-36, 2006.

[19] J. Zhang, Q. Lian, J. R. Wang, and F. Chen, “The experimental study on making use of manganese dregs to prepare ceramic wall and floor tile," China Ceramic Industry, vol. 16, no. 3, pp. 16-19, 2009.

[20] Y. Wang, N. C. Zhang, and W. H. Ye, "Method for the manufacture of bricks from electrolytic manganese-production slag, suitable for reducing environmental pollution and energy consumption," CN, 01644089 [P], 2010.

[21] X. H. Jiang, Z. Wang, P. K. Hou, J. S. Qian, and J. P. Cao, "Experimental study on preparation of non-burnt brick from electrolytic manganese residue," Non-Metallic Mines, vol. 33, no. 1, pp. 14-17, 2010.

[22] C. S. Poon, S. C. Kou, and L. Lam, "Use of recycled aggregates in molded concrete bricks and blocks," Construction and Building Materials, vol. 16, no. 5, pp. 281-289, 2002.

[23] P. Chen, Z. J. Wang, and R. J. Liu, "Experimental study on concrete of manganese slag in different dosage," Concrete, vol. 2, pp. 71-73, 2010.

[24] J. Xie and H. M. Bao, "Study on service test of cement mortar and concrete mixed with manganic sinter," Subgrade Engineering, no. 5, pp. 156-158, 2007.

[25] Y. L. Wang, P. Chen, T. Liu, and J. R. Liu, "Experimental research of admixtures prepared with ferromanganese slag," Journal of Guilin University of Electronic Technology, vol. 29, no. 6, pp. 507510, 2009. 

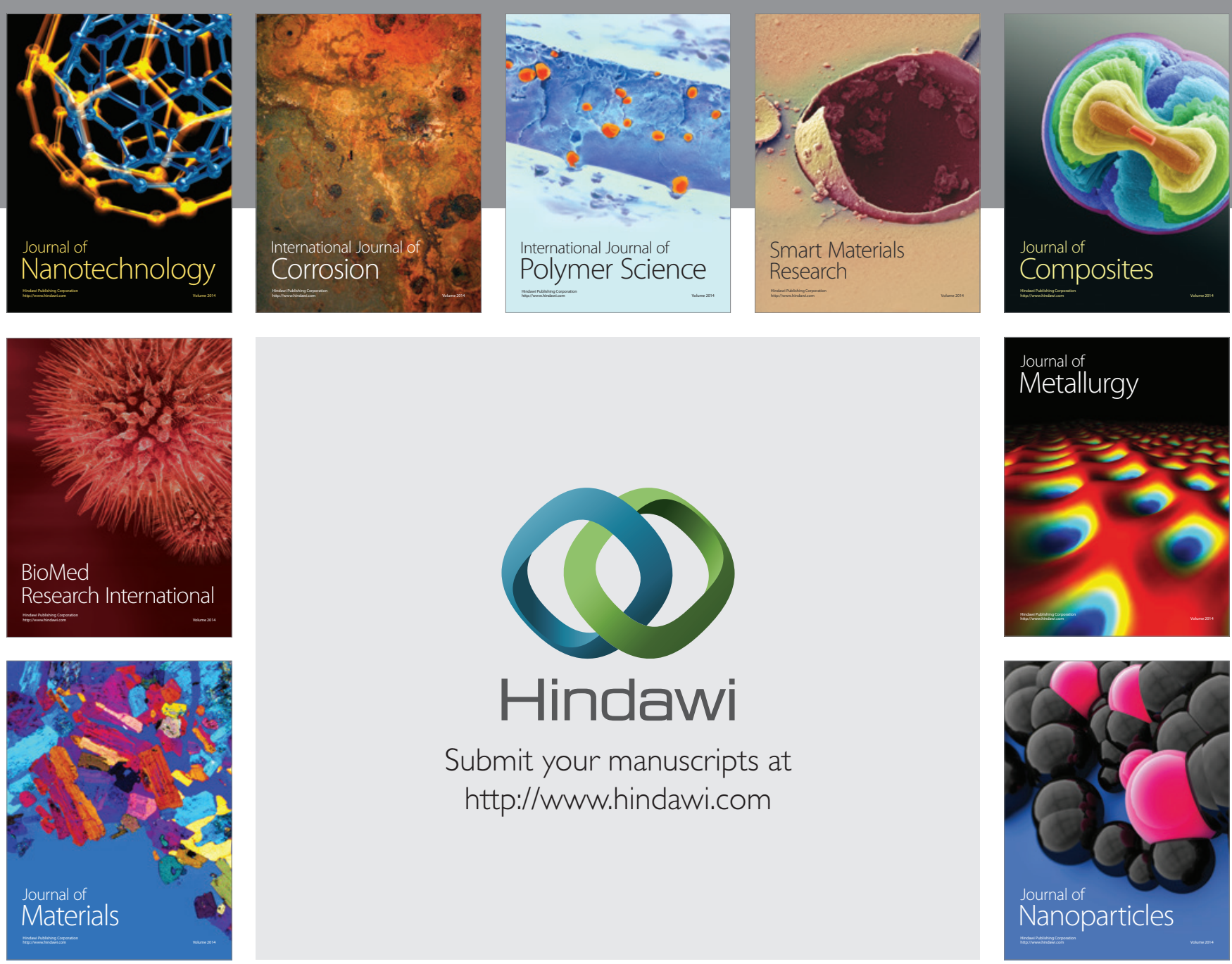

Submit your manuscripts at http://www.hindawi.com
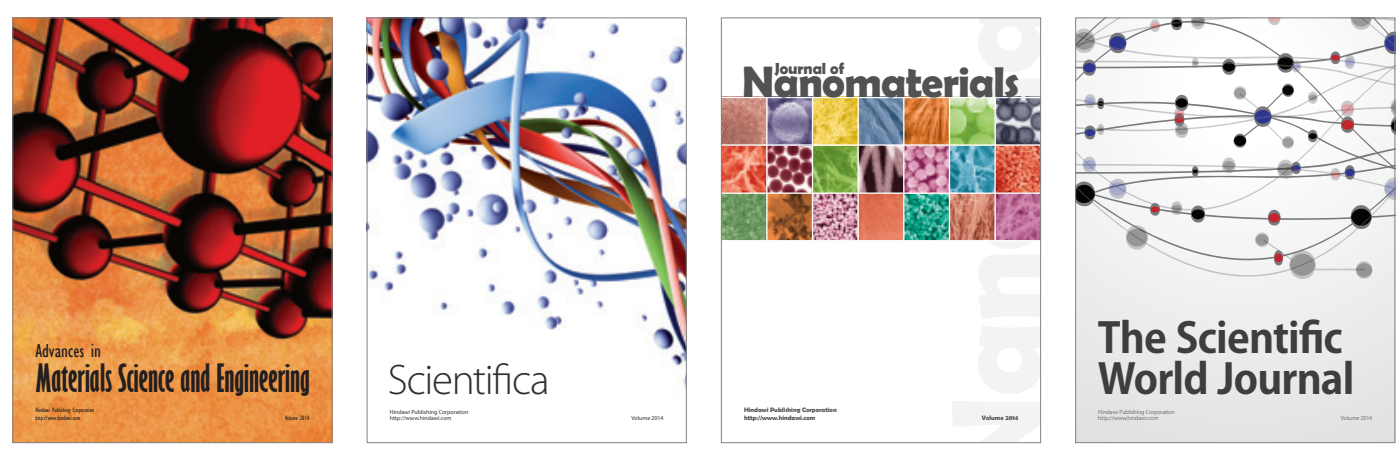

\section{The Scientific World Journal}
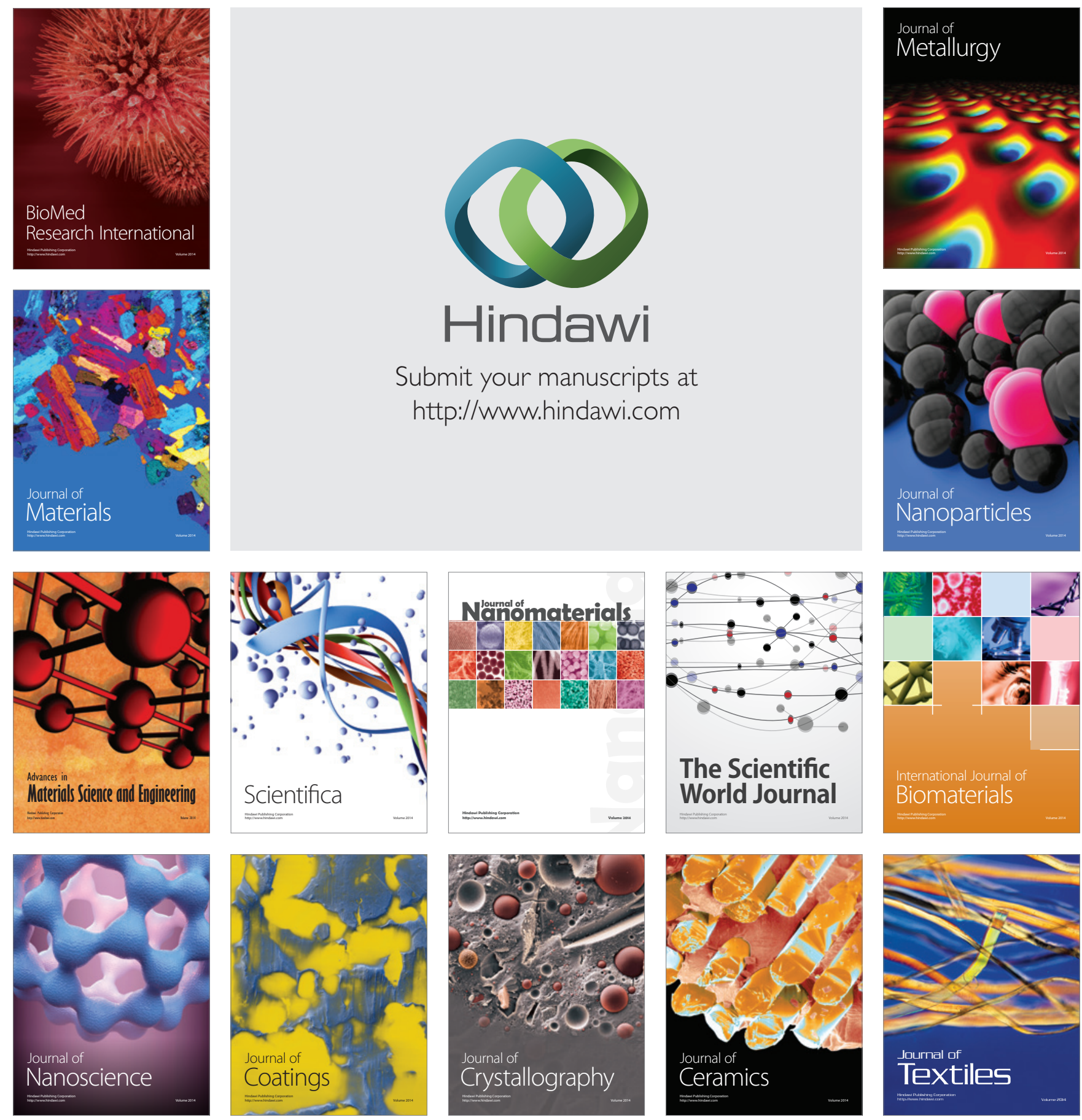